\title{
Influence of density on intraguild predation of aquatic Hemiptera (Heteroptera): implications in biological control of mosquito
}

\author{
S. Brahma, ${ }^{1}$ G. Aditya, ${ }^{1,2}$ D. Sharma, ${ }^{1}$ N. Saha, ${ }^{1}$ M. Kundu, ${ }^{2}$ G.K. Saha ${ }^{1}$ \\ ${ }^{1}$ Department of Zoology, University of Calcutta, Kolkata; ${ }^{2}$ Department of Zoology, The University \\ of Burdwan, Golapbag, India
}

\begin{abstract}
The water bugs Diplonychus rusticus (Fabricius) (Heteroptera: Belostomatidae) and Anisops bouvieri (Kirkaldy) (Heteroptera: Notonectidae) co-occur in wetlands sharing mosquito larvae as prey. As a consequence, an asymmetrical intraguild predation (IGP) involving $D$. rusticus as IG predator and $A$. bouvieri as IG prey can be possible, the outcome of which may vary with the relative density of interacting species. Based on this proposition density dependent effects on the IG prey and shared prey mortality were assessed in the laboratory using varying numbers of IG predator and shared prey (IV instar Culex quinquefasciatus larva). In contrast to single predator system, mosquito larvae were proportionately less vulnerable to predation in IGP, at low density of shared prey. An increase in density of mosquito decreased the mortality of IG prey (A. bouvieri), but the mean mortality of the IG prey
\end{abstract}

Correspondence: Goutam K. Saha, Department of Zoology, University of Calcutta, 35 Ballygunge Circular Road, Kolkata 700019, India

Tel.: +91.33.2461.5445 - Fax: +91.33.2461.4849.

E-mail: gkszoo@rediffmail.com

Key words: Heteroptera, Diplonychus rusticus, Anisops bouvieri, intraguild predation, density.

Acknowledgements: the authors acknowledge the respective Heads, Department of Zoology, University of Calcutta, Kolkata and The University of Burdwan, Burdwan, India for the facilities provided, including DST-FIST and UGC-DRS SAP-II.

Funding: GA acknowledges the financial assitance of UGC through Research Award [Sanction No F.30-90(SA-II)/2009;17.09.2009] in carryng out the work. SB acknowledges the financial assistance of UGC-RFSMS in carrying out this work.

Received for publication: 11 October 2013

Revision received: 11 November 2013.

Accepted for publication: 19 November 2013.

CCopyright S. Brahma et al., 2014

Licensee PAGEPress, Italy

Journal of Entomological and Acarological Research 2014; 46:1977

doi:10.4081/jear.2014.1977

This article is distributed under the terms of the Creative Commons Attribution Noncommercial License (by-nc 3.0) which permits any noncommercial use, distribution, and reproduction in any medium, provided the original author(s) and source are credited. increased with the density of IG predator, in IGP system. Increase in density of mosquito and $D$. rusticus enhanced risk to predation of mosquito while reducing the mortality of $A$. bouvieri. Interaction between $D$. rusticus and A. bouvieri as a part of IGP system provides a possible reason of coexistence of mosquito immature along with predators in wetlands. Biological regulation of mosquitoes may be affected, if appropriate predator numbers are not available in the habitats.

\section{Introduction}

Coexistence of multiple insect predators of mosquitoes is observed in mosquito larval habitats like rice fields and similar wetlands (Sunish \& Reuben, 2002; Bambaradeniya et al., 2004; Das et al., 2006; Banerjee et al., 2010). In contrast to a single predator, the presence of multiple predators increases the possibility of sharing mosquito prey, thereby increasing the complexity of food web. Resource sharing by predators implies a degree of competition that may manifest as intraguild predation (IGP) system. In IGP, the shared prey is linked to both the intraguild predator (IG predator) and the intraguild prey (IG prey). In isolation, both the IG predator and the IG prey impart a different level of regulation on the shared prey. Thus IGP system is a distinct phenomenon involving predators that compete with each other for shared resource. The outcome of IGP on the shared prey vary with the identity (Polis et al., 1989; Arim \& Marquet, 2004) and relative numbers (Denno et al., 2002; Balfour et al., 2003; Borer et al., 2003; Walzer et al., 2004) of interacting taxa, signifying that IGP influences stability and diversity of species ensembles (Walls \& Williams, 2001; Crumrine \& Crowley, 2003; Rosenheim \& Corbett, 2003). Considering biological control of mosquito, the influence of the top predator on the IG prey and mosquito larvae would determine the degree of regulation and efficacy of the biocontrol agent.

Prey consumption by multiple predators can be more than or less than expected based on the individual consumption by the predators (Sih et al., 1998). If the expected prey consumption is greater than observed, it indicates a synergistic effect of predation (Soluk \& Collins, 1988; Soluk, 1993), augmenting the risk of predation on the target prey (Crumrine \& Crawley, 2003; Crumrine, 2005). In situations when shared prey consumption is less than expected, it can be due to the interference competition with the intraguild prey. The interactions between IG prey and IG predator can influence the population of the shared prey, since the IG prey become vulnerable to intraguild predation that would mean a reduced number of available predators and shifting of prey choice by the top predator (Crumrine \& Crowley, 2003). However, in IGP system, the consequence on shared prey is expected to vary with its own relative density in contrast to the IG prey and IG predators in the community. To test these propositions, the present study considered Diplonychus rusticus Fabricius, 1781 
(Heteroptera: Belostomatidae) as IG predator, Anisops bouvieri Kirkaldy, 1741 (Heteroptera: Notonectidae) as the IG prey and IV instar larvae of Culex quinquefasciatus Say, 1823 (Diptera: Culicidae) as shared prey. Often the IGP system is classified as symmetric or asymmetric based on the role of the constituent predator species as IG predator and IG prey. In symmetric IGP system, the role of predators may change, based on ontogeny or biomass; while in asymmetric IGP system, the role of the predator species remain unchanged as IG predator and IG prey. The IG predator D. rusticus, and the IG prey A. bouvieri, considered in the present study constitute an asymmetrical IGP system. These predatory insects and the mosquito prey are common in many of the tropical wetlands including rice fields (Sunish \& Reuben, 2002; Bamabaradeniya et al., 2004; Das et al., 2006; Banerjee et al., 2010). The dietary choice of these predators includes mosquitoes as a component which makes them suitable as mosquito control agent (Aditya et al., 2004, 2005; Saha et al., 2007a, 2007b; Banerjee et al., 2010). Earlier studies indicate that the mosquito prey consumption of $D$. rusticus, and A. bouvieri vary with the relative density (Aditya et al., 2005; Saha et al., 2010), light availability (Saha et al., 2008) and habitat complexity (Saha et al., 2009). In view of the predatory behavior of these water bugs, relative density of prey and predators can be useful explanatory factors to infer about the effect of density on the mosquito larvae as shared prey in IGP system. Thus, density dependent effects in IGP system involving the heteropteran predators and mosquito prey are being addressed in the present study. The results are expected to highlight the interaction between the insect predators and mosquito prey and indicate the biocontrol efficacy of these insect predators of mosquito. Earlier studies have shown that the mosquito fish Gambusia affinis could not reduce the mosquito population effectively in the rice fields owing to shifting in prey consumption that included beetles and bugs which are themselves predators of mosquito larvae (Bence, 1988; Blaustein, 1992). Interactions among potential mosquito predators may be a reason favoring abundance of mosquitoes even in presence of multitude of predators in the mosquito larval habitats like rice fields and temporary pools. In the present instance the co-occurrence of the predators and the mosquito may possibly due to such interaction between the predators D. rusticus and A. bouvieri, which could be revealed through the assessment of density dependent effects on the shared prey and the IG prey. In IGP system of larval odonates (Crumrine \& Crowley, 2003; Crumrine, 2005; Flynn \& Moon, 2011; Lupi et al., 2013), shared prey abundance influence consumption of both shared prey and IG prey mortality. Assuming similar manifestations in heteropteran mosquito predator guild, effects of predator and shared prey density on IG prey and shared prey mortality were tested in the present study to deduce feasibility of biological control of wetland mosquitoes using insect predators.

\section{Materials and methods}

\section{The insect predators}

Adult morphs of the water bugs A. bouvieri and D. rusticus were collected from the ponds behind Ballygunge Science College campus, University of Calcutta, Kolkata and from the wetlands along Eastern Metropolitan bypass, Kolkata. An insect net of $200 \mu \mathrm{m}$ mesh size fixed to a long handle was used for collection of $D$. rusticus and $A$. bouvieri from the ponds. The collected insects were brought to the laboratory and were kept separately in glass aquaria containing $35 \mathrm{l}$ of tap water, with few macrophyte specimens such as Chara sp. and Vallisneria sp. to simulate natural conditions. Mosquito larvae were provided as food every day. This setup was kept for at least seven days before commencement of the experiment. The body length of the predators was measured from tip of the rostrum to the end of the abdomen; the average body length of $D$. rus- ticus used in this experiments was $16.4 \mathrm{~mm}$ (range, $15-18 \mathrm{~mm}$ ), the one of $A$. bouvieri was $6.32 \mathrm{~mm}$ (range, 5.8-7.2 mm).

\section{The prey}

The mosquito larvae $C$. quinquefasciatus were collected from the sewage drains in and around Ballygunge Science College campus, University of Calcutta, Kolkata. The collected larvae were brought to the laboratory and placed in an enamel tray $\left(30 \times 20 \times 10 \mathrm{~cm}^{3}\right)$ for segregation of the IV instar larvae (5.1-6.0 mm in length, IV instar; 1.9-2.1 mg in weight) to be used in the experiments. The collection of mosquito larvae was continued, as and when required, in course of the experiment.

\section{Experimental design}

The experiments were conducted in glass aquaria $\left(38 \times 36 \times 36 \mathrm{~cm}^{3}\right)$ using $35 \mathrm{~L}$ of water (aged tap water and pond water in a ratio of $1: 1 ; \mathrm{pH}$ 7.9-8.1) under room temperature $\left(27-30^{\circ} \mathrm{C}\right)$ in a light (L): dark (D) cycle of 13D:11L h. Using four different densities of mosquito larvae viz. 50, 100, 200 and 400, and different predator combinations, three experiments were carried out in replicates.

In the first experiment, D. rusticus was used as a predator in three different densities of 1, 2 and 4 individuals. For each density level of the predator, mosquito larvae were provided in four different densities, and the numbers of mosquito larvae consumed were recorded at the end of $24 \mathrm{~h}$ period. A total of 216 replicates was carried out in this experiment ( 3 predator density $\times 4$ mosquito prey density $\times 18$ trials $=216$ replicates).

In the second experiment, A. bouvieri was used as a predator in a single density of 10 individuals. Mosquito larvae were provided as prey in four different densities, and the numbers of mosquito larvae consumed were recorded at the end of $24 \mathrm{~h}$ period. A total of 72 replicates was carried out in this experiment ( 1 predator density $\times 4$ mosquito prey density $\times 18$ trials $=72$ replicates $)$.

In the third experiment, D. rusticus and A. bouvieri were considered as IG predator and IG prey respectively, in three different combinations viz. 1:10, 2:10 and 4:10 at each of the mosquito larval (shared prey) densities. The number of mosquito larvae (shared prey) and the IG prey (A. bouvieri) consumed at the end of $24 \mathrm{~h}$ period was recorded. This experiment constituted an IGP system, and a total of 216 replicates was carried out ( 3 IG predator density $\times 4$ shared prey density $\times 18$ trials).

In all the experiments, a predator was used in a single trial only. The experimental trials were carried out at different time interval such that each trial represents a true replicate (Hurlbert, 1984).

The data obtained on shared prey mortality and IG prey mortality were separately subjected to two- way factorial ANOVA (Zar, 1999) using prey density and predator combinations as explanatory factor for prey mortality. Size effects of the predator and prey density in explaining the observed variation on the prey mortality was estimated through partial $\eta^{2}$ (eta square) (Zar, 1999).

\section{Risk to predation analysis}

Shared prey (i.e. mosquito larvae) vulnerability in the form of risk of predation to individual predator type and in intraguild predation system was assessed by using the formula of Crumrine \& Crowley (2003) and Crumrine (2005) to observe the effect of IG prey on the consumption of shared prey by IG predator. According to the formula the shared prey and IG prey mortality rate $\left(\mathrm{k}_{\mathrm{i}}\right)$ was determined for each replicate of treatment (i) over the trial duration $\mathrm{t}(=24 \mathrm{~h})$. Proportion of prey killed was assumed as $\mathrm{p}_{i}$ and thus the proportion surviving is $\left(1-\mathrm{p}_{i}\right)$ :

$1-\mathrm{p}_{i}=\mathrm{e}^{-\mathrm{k}_{i}^{\mathrm{t}}}$

or

$\mathrm{k}_{i}=-\ln \left(1-\mathrm{p}_{i}\right) / \mathrm{t}$ 
Accordingly for $A$. bouvieri and $D$. rusticus predation on mosquito, if $\mathrm{k}_{\mathrm{A}}$ is assumed as shared prey mortality in the presence of IG prey $A$. bouvieri alone and $\mathrm{k}_{\mathrm{D}}$ is the shared prey mortality in the presence of $D$. rusticus alone, then the null hypothesis for predation when both are present is:

$\mathrm{k}_{\mathrm{A}}+\mathrm{k}_{\mathrm{D}}=\mathrm{k}_{\mathrm{A}+\mathrm{D}}$

Expected value for the joint predation can be generated by summation of proportional prey consumption by two predator species when present alone. When summation of individual effect is equal to combined effect of both predators i.e. $\mathrm{k}_{\mathrm{A}}+\mathrm{k}_{\mathrm{D}}=\mathrm{k}_{\mathrm{A}+\mathrm{D}}$, it may be assumed that IGP is absent on the prey consumption by the top predator. If Observed $\mathrm{k}_{\mathrm{A}+\mathrm{D}}<$ Expected $\mathrm{k}_{\mathrm{A}}+\mathrm{k}_{\mathrm{D}}$, this implies risk reduction in prey mortality and favors prey survival, but when Observed $\mathrm{k}_{\mathrm{A}+\mathrm{D}}>$ Expected $\mathrm{k}_{\mathrm{A}}+\mathrm{k}_{\mathrm{D}}$, then it indicates higher number of prey mortality i.e. risk enhancement occurs. A two- tailed t-test was applied to find out significant deviation of the ratio of Observed $\mathrm{k}_{\mathrm{A}+\mathrm{D}}$ / Expected $\mathrm{k}_{\mathrm{A}+} \mathrm{k}_{\mathrm{D}}$ from unity (Zar, 1999). The term risk reduction and risk enhancement originates from the null additive models (Soluk \& Collins, 1988) and explanation regarding multiple predator effects (Sih et al., 1998). We assumed that interactions between the IG predator, IG prey and the shared prey as a multiple predator effect and used the model of Crumrine \& Crowley (2003) and Crumrine (2005) to analyze the risk reduction and risk enhancement on the shared prey. The effect of density of the shared prey and IG predator on the risk reduction and risk enhancement for the shared prey and the IG prey was assessed.

\section{Results}

The mortality of the mosquito prey (C. quinquefasciatus IV instar larva) varied with the combinations and effective number of predators present. The prey mortality due to consumption by the IG predator $D$. rusticus and the IG prey A. bouvieri varied with the relative densities of the mosquito prey available when present separately as well as IGP system. Density impact of the IG predator on the mortality of the mosquito prey was also evident. However, at the highest density of mosquito, a fourfold increase in density of the IG predator resulted in 30 percent increment in number of prey consumed (Figures 1 and 2). The number of mosquito prey consumed under these conditions is shown in Figure 2. The two way factorial ANOVA revealed significant differences in the prey mortality as a function of prey and IG predator relative densities (Tables 1 and 2). The partial $\eta^{2}$ was higher for prey density factor than predator density suggesting that the prey density contributed to higher variability of shared prey mortality. In IGP system, the mortality of the IG prey A. bouvieri reduced with increasing mosquito prey density, although relative mortality of IG prey increased with the IG predator density (Figure 3). The two-way ANOVA results (Tables 3 and 4) suggest significant effect of shared prey density on the mortality of IG prey. Thus, two levels of density effect on the shared prey mortality were observed in all experimental trials: i) with increase in density the mortality of mosquito (IV instar $C$. quinquefasciatus larva) increased, both in single predator and IGP system; ii) increase in density of mosquito (shared prey) resulted in decreased mortality of the IG prey (A. bouvieri), but the mean mortality of the IG prey increased with the density of IG predator (D. rusticus), in IGP system.

As a part of IGP system, the risk to predation for mosquito larvae was higher at higher relative density, while at lower densities it was low (Figure 4). For all the IG predator densities, the Observed $k_{A+D}$ /Expected $\mathrm{k}_{\mathrm{A}+} \mathrm{k}_{\mathrm{D}}$ values were consistently less than 1 when the initial shared prey densities were 50 and 100 , while the values were greater than 1 when the initial shared prey densities were 200 and 400 . The results of the t-test suggest significant $(\mathrm{P}<0.001)$ deviations from the lower than expected values $(<1)$ and greater than expected values $(>1)$ (Table 5). This suggests that the increase in relative density of mosquito larvae (shared prey) increases the risk of predation possibly as an additive effect while reducing the mortality of $A$. bouvieri (IG prey) simultaneously.

\section{Discussion and conclusions}

The prey consumption pattern of the IG predator (D. rusticus) and IG prey (A. bouvieri) in single predator experiments remained similar to the observations made in earlier studies (Saha et al., 2007a, 2007b, 2009,2010 ). The predation on mosquito larvae by these heteropteran predators is density-dependent (Aditya et al., 2004; Saha et al., 2007a, 2007b) with switching to abundant prey size (Aditya et al., 2005) and species (Saha et al., 2009, 2010). This is reflected in the single predator experiments where the prey mortality increased with increased density of prey and IG predator. Similar effect of density on mosquito mortality was observed in IGP system. The mortality of the A. bouvieri (IG prey) decreased with increased shared prey density but the relative mortality increased with IG predator (D. rusticus) density levels. Thus density of IG predator resulted in increased mortality in both shared prey and IG prey. Low density of mosquito reduced its risk to predation and increased mortality of IG prey was observed. This is comparable to the observation on the density-dependent and species-specific mortality of larvae of mayfly subjected to individual and joint predation by sculpins and stoneflies. Interference between predators resulted in reduced predation of Baetis at moderate and high prey density while facilitation between predators increased mortality of Ephemerella at low and moderate densities (Soluk, 1993). In the present instance, the

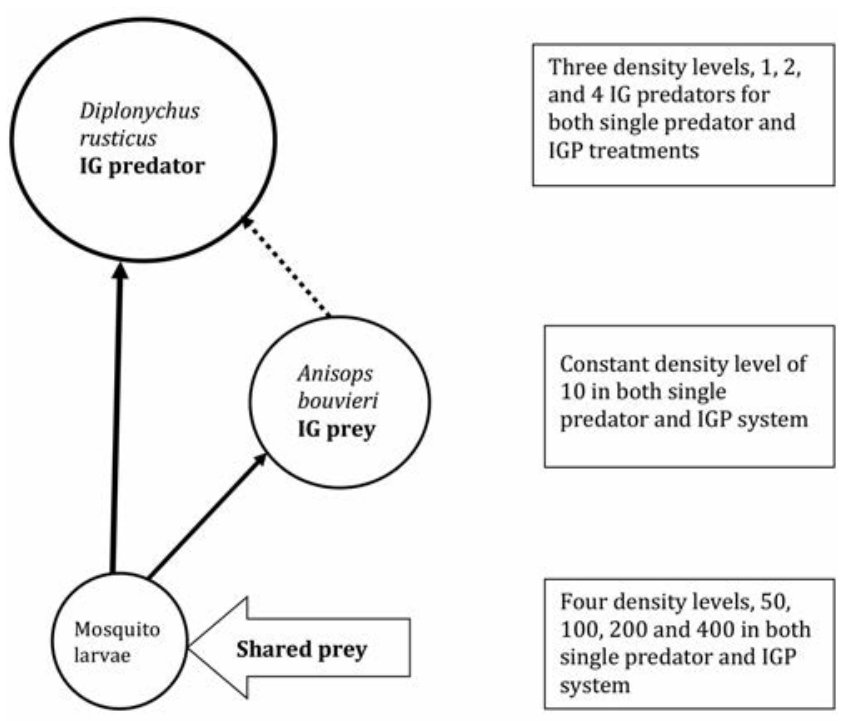

Figure 1. Schematic representation of the trophic relations among the mosquito prey and heteropteran predators, considered in the study. The arrows are directed towards the predator and the thickness of the arrows are proportionate to the numbers consumed. Single prey-predator interactions are shown by continuous arrows and inclusion of dashed arrow indicates the intraguild predation (IGP) system. Experiments were carried out using single predator and both predators (IGP system) with the density levels stated in the right hand side. 
IGP interaction between the predators favoured mosquitoes at lowshared prey density but the effect diminished at high shared prey density. We assume that at low shared prey density with random encounter of prey, the probability of encounter with $A$. bouvieri was higher contrast to the mosquito prey and this could account for reduced proportionate mosquito mortality. Risk reduction is common when predatorpredator interactions are probable and more specifically among predators that vary in size (Crumrine, 2005). In addition, density effects of the IG predator and the shared prey can modify the multiple predator effect and the shared prey and IG prey mortality.

Studies on amphibian IGP demonstrate that increase in density of tadpole of wood frog Rana sylvaticus (IG predator) resulted in increased egg predation and reduced growth of the spotted salamander Ambystoma maculatum (IG prey) (Burley et al., 2006). This interaction resulted in reduced hatchling number of $A$. maculatum but enhanced larval development. Similarly in the present context, the relative risk of predation was low when the density of the mosquito prey was low but increased at higher density. This is significant in terms of the prey predator interaction in wetlands. In habitats like ricefields and allied

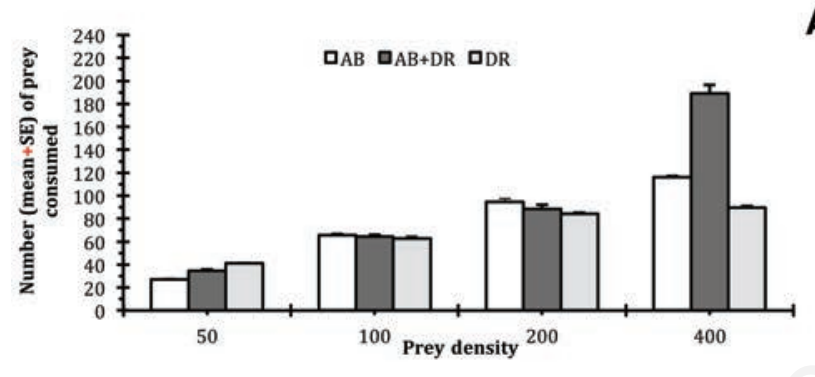

A)

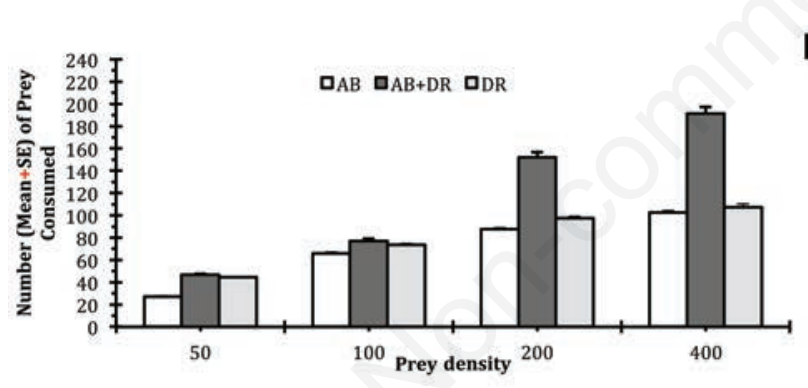

B)

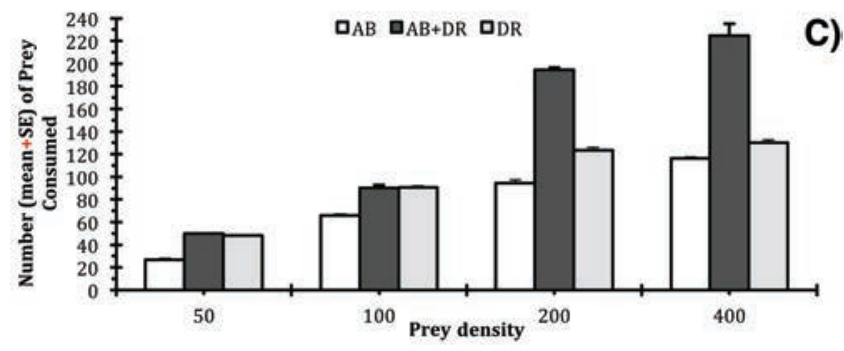

Figure 2. (A-C) The number (mean $+\mathrm{SE})$ of shared prey (mosquito larva) consumed by intraguild (IG) predator D. rusticus (DR) and IG prey $A$. bouvieri $(\mathrm{AB})$ in isolation and in combinations at different initial prey densities and different predator combinations (A: IG predator 1: 10 IG prey; B: IG predator 2: 10 IG prey; and C: IG predator 4: 10 IG prey) (n=18 trials per combinations per prey density). wetlands, the mosquito prey densities vary with time and the colonization pattern follow a succession sequence (Dale \& Knight, 2008), along with co-occuring macro invertebrates. In the initial stage of rice plantation, mosquito prey density is low followed by the concurrent invasion of the heteropteran predators (Lawler \& Dritz, 2005). Under such situation the mortality of IG prey can be higher to complement the dietary requirements of $D$. rusticus, provided the availability of other prey is low. With time, the complexity of the aquatic species assemblages in rice fields increase and the density of the mosquito prey increases too. Risk enhancement of mosquitoes can be anticipated when the predation from both the predators increase. The results of the present study support this proposition. Studies on the IGP system on water scorpion Laccotrephes japonensis as IG predator demonstrated that the smaller instar nymph of Kirkaldyia deyrolli (IG prey) were consumed at a higher rate than the shared prey - larger instar of Appasus japonicas and tadpoles of Hyla japonica (Ohba \& Swart, 2009). Field and laboratory observations reveal that predation pressure of $L$. japonensis on smaller instar of $K$. deyrolli reduces with increase in the density of the shared prey - tadpoles (Ohba \& Nakasuji, 2007), signifying density mediated effects on IGP. In larval odonates, interactions between Sympetrum vicinum (dragonfly) and Enallagma civile (damselfly) varied with the shared prey abundance, prey identity and habitat complexity. When prey abundance was low, the wet mass of $E$. civille was affected in contrast to the conditions, when the shared prey was high (Flynn \& Moon, 2011). Preceding examples and observations on the wetland insect assemblages (Bambaradeniya et al., 2004; Banerjee et al., 2010) indicate that: i) IGP system is common in heteropteran predators of wetlands; and ii) the prey preference is crucial in the outcome of such multiple prey-predator interactions. In the present instance, the mortality of the IG prey (A. bouvieri) was dependent on the relative density of IG

Table 1. Results of two way factorial ANOVA, using prey density and predator density as explanatory variables for the mosquito larval (shared prey) mortality in presence of both intraguild predator and guild predator prey.

\begin{tabular}{lcccc} 
Source & df & Mean square & F & Partial $\eta^{2}$ \\
PRD & 2 & $62,169.93$ & $167.08^{*}$ & 0.443 \\
PD & 3 & $558,706.85$ & $1501.52^{*}$ & 0.915 \\
\hline PRD $\times$ PD & 6 & $10,440.17$ & $28.06^{*}$ & 0.286 \\
Error & 420 & 372.09 & - & - \\
\hline Total & 431 & - & - & - \\
\hline PRD, predator density; $P D$, prey density. *-values indicate significance at P $<0.05$ level.
\end{tabular}

Table 2. Results of post hoc Tukey test, using prey density and predator density as explanatory variables for the mosquito larval (shared prey) mortality in presence of both intraguild predator and IG prey.

\begin{tabular}{|c|c|c|c|c|c|}
\hline \multicolumn{3}{|c|}{$\begin{array}{l}\text { Predator density: } \\
\text { SE }=2.27 \text {; df }-420.2\end{array}$} & \multicolumn{3}{|c|}{$\begin{array}{c}\text { Prey density: } \\
\text { SE=2.62; df }-420.3\end{array}$} \\
\hline (I) & (J) & I-J & (I) & (J) & I-J \\
\hline 1 & 2 & $-16.06^{*}$ & 50 & 100 & $-30.83^{*}$ \\
\hline 1 & 4 & $-41.22 *$ & 50 & 200 & $-107.2^{*}$ \\
\hline 2 & 4 & $-25.17^{*}$ & 50 & 400 & $-158.1^{*}$ \\
\hline- & - & - & 100 & 200 & $-76.37^{*}$ \\
\hline- & - & - & 100 & 400 & $-127.3^{*}$ \\
\hline - & - & - & 200 & 400 & $-50.93^{*}$ \\
\hline
\end{tabular}

${ }^{*}$ F-values indicate significance at $\mathrm{P}<0.05$ level. 
predator (D. rusticus) and shared prey densities. We predict that the variations in the relative densities of the IG prey and shared prey determine the outcome of prey-predator interactions in the IGP system. When the densities of the shared prey are high the prey consumption of the IG predator is highly inclined towards the shared prey. The additive effects of the two predators - IG predator and the IG prey - on the shared prey mortality reflects that the risk to predation increases with the increase in the density of the mosquito prey. Increase in number of IG predator, not only increased the ratio of IG predator and IG prey but also increased the overall predator density. While interpreting the predator density effects on shared prey mortality, it seems that higher number of IG predators increased vulnerability of both shared prey and IG prey, proportionate to the availability of shared prey.

In several studies demonstrating IGP system, the resultant effect on the shared prey varied with the predator and prey densities (Wissinger, 1992; Wissinger \& McGrady, 1993; De Clercq et al., 2003; Okuyama \& Ruyle, 2003; Holbrook \& Petranka, 2004; Flynn \& Moon, 2011). The body size of the IG prey and the shared prey are highly disproportionate and

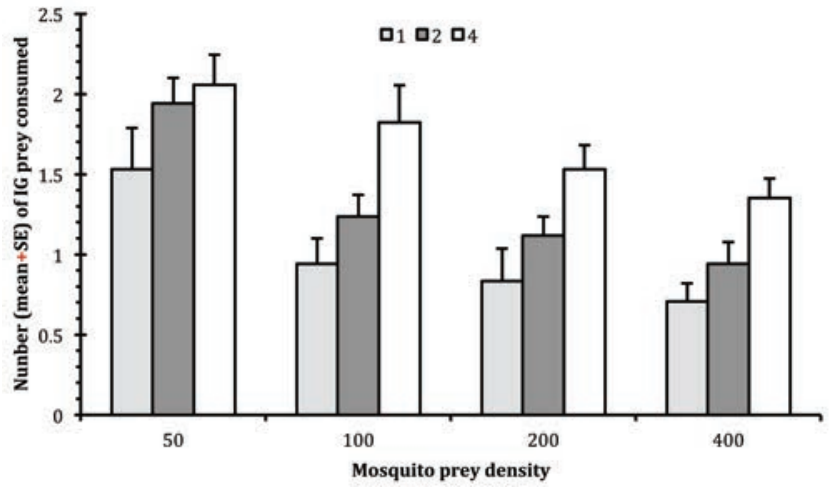

Figure 3. The number (mean+SE) of $A$. bouvieri (IG prey) consumed as a function of initial shared prey density and intraguild (IG) predator density (1, 2 and 4).

Table 3. Results of two way factorial ANOVA, using shared prey density and intraguild (IG) predator density as explanatory variable for $A$. bouvieri (IG prey) mortality in presence of both IG predator and IG prey.

\begin{tabular}{lcccc} 
Source & df & Mean square & F & Partial $\eta^{2}$ \\
PRD & 2 & 8.39 & $18.18^{*}$ & 0.151 \\
PD & 3 & 7.34 & $15.89^{*}$ & 0.189 \\
\hline PRD $\times$ PD & 6 & 0.23 & 0.49 & 0.014 \\
Error & 204 & 0.47 & - & - \\
\hline Total & 215 & - & - & -
\end{tabular}

PRD, predator density; $\mathrm{PD}$, prey density. ${ }^{*} \mathrm{~F}$-values indicate significance at $\mathrm{P}<0.05$ level.

Table 4. Results of post hoc Tukey test, using shared prey density and intraguild (IG) predator density as explanatory variable for A. bouvieri (IG prey) mortality in presence of both IG predator and IG prey.

\begin{tabular}{|c|c|c|c|c|c|}
\hline \multicolumn{3}{|c|}{$\begin{array}{l}\text { Predator density: } \\
\text { SE=0.11; df=204.2 }\end{array}$} & \multicolumn{3}{|c|}{$\begin{array}{c}\text { Prey density: } \\
\text { SE }=0.13 ; \mathrm{df}=204.2\end{array}$} \\
\hline (I) & (J) & I-J & (I) & (J) & I-J \\
\hline 1 & 2 & $-0.292 *$ & 50 & 100 & $0.5185^{*}$ \\
\hline 1 & 4 & $-0.681^{*}$ & 50 & 200 & $0.6852^{*}$ \\
\hline 2 & 4 & $-0.389 *$ & 50 & 400 & $0.8519 *$ \\
\hline - & - & - & 100 & 200 & 0.16667 \\
\hline- & - & - & 100 & 400 & 0.33333 \\
\hline - & - & - & 200 & 400 & 0.16667 \\
\hline
\end{tabular}

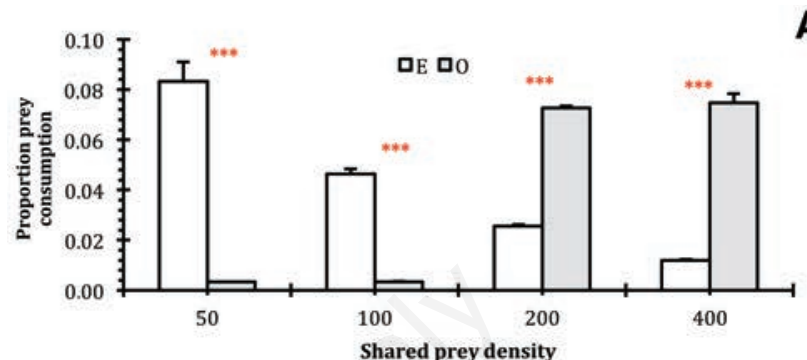

A)

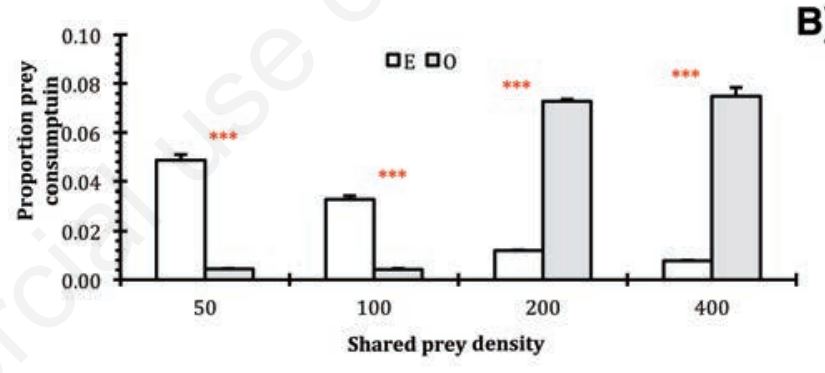

C)

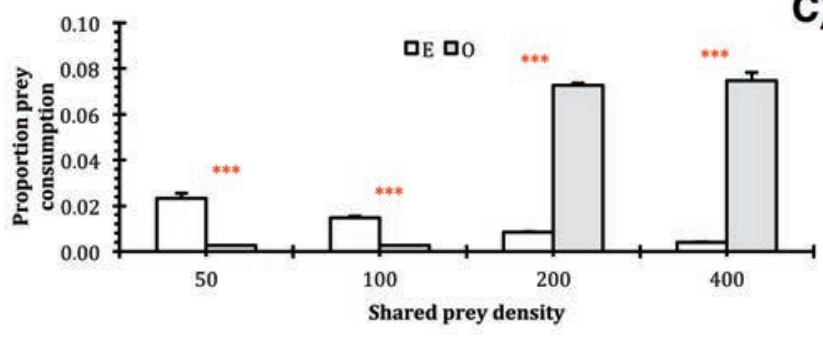

Figure 4. The risk to predation index $($ mean+SE) for mosquito larvae (shared prey) at different initial densities against different intraguild (IG) predator: IG prey ratio and numbers (A: 1:10; B: $2: 10 ; C: 4: 10)$. $E=$ Expected $k_{A+} k_{D}, O=O b s e r v e d ~ k_{A+D}$. Irrespective of density of IG predator and shared prey, the observed and expected values were different significantly at $\mathbf{P}<0.001$, marked as ***.

Table 5. The results of $t$-test to justify differences in the expected and observed values in the index of risk of predation. All $t$-values are significant at $\mathbf{P}<0.001$ level (two-tailed), at $\mathbf{~ d f ~}-17$.

\begin{tabular}{lcccc} 
IG predator density & \multicolumn{4}{c}{ Initial shared prey density (numbers) } \\
& 50 & 100 & 200 & 400 \\
1 & $\mathrm{t}=614.39$ & $\mathrm{t}=206.13$ & $\mathrm{t}=22.29$ & $\mathrm{t}=15.31$ \\
2 & $\mathrm{t}=127.37$ & $\mathrm{t}=65.12$ & $\mathrm{t}=35.32$ & $\mathrm{t}=15.016$ \\
\hline 4 & $\mathrm{t}=214.54$ & $\mathrm{t}=278.09$ & $\mathrm{t}=27.97$ & $\mathrm{t}=17.37$ \\
\hline IG, intraguild. & & & &
\end{tabular}


inclined towards the IG prey inviting the IG predator to consume more of the IG prey than shared prey. However, this was not exhibited at higher densities of mosquito, providing a reasonable basis to conclude that mosquitoes are preferred than the backswimmers, although the energy returns are higher for the latter. This may be favourable for mosquito control using water bugs. In mosquito larval habitats both the IG predator and the IG prey co-occur with mosquito larvae (Sunish \& Reuben, 2002; Bambaradeniya et al., 2004; Banerjee et al., 2010). Therefore predatory interference between these insects is inevitable. We assume that the risk to predation of mosquito larvae (shared prey) will vary with its relative density and the relative densities of the IG predator. Interactive effect of the IG predator and the IG prey insects will reduce mosquitoes at a higher proportion, when the density of the shared prey is high than when the density is low. From biological control viewpoint, IGP system seems to be favourable if mosquito density is high along with higher relative densities of the predators. The mosquito larval habitats are heterogenous with the presence of multiple predators and physical structures including debris and detritus (Saha et al., 2008; Banerjee et al., 2010). Ability to judge the presence of predators and quality of the habitat restrain mosquitoes from oviposition in larval habitats as evident from the studies on Culex tritaeniorhynchus (Ohba et al., 2012) and Culiseta longiareolata (Blaustein et al., 2004). Avoidance of predators in natural situations may influence the outcome of the prey predator interactions as observed in the present instance. In many situations, the larval habitats like rice fields and allied wetlands forma mosaic space to sustain metacommunity. Dispersal of the predatory insects is obvious in such situations as observed for the beetles Graphoderus occidentalis and Rhantus sericans (Yee et al., 2009; Yee, 2010). Variation in abundance of the predatory insects and the avoidance of habitats by mosquito prey may influence outcome of the prey-predator interactions which need to be evaluated further to comment on the utility of the IGP system under field conditions. Habitat complexity influences the outcome of IGP system as evidenced from the studies of larval odonata (Flynn \& Moon, 2011). The identity of the IG predator and the IG prey may also be important factor since cannibalism and inter specific predation are common among the various heteropteran species common in the wetlands. While considering heteropteran species for biological control, predator species substitutability (Sih et al., 1998; Crumrine, 2005) may be important in successful regulation of mosquitoes. Nonetheless, the present study reflects that the relative density of the IG predator and IG prey are important determinants in the outcome of the IGP system and the resultant impact on the shared prey, mosquito larvae. In view of biological control of mosquitoes in wetland habitats, the insect predators $D$. rusticus and A. bouvieri should be present in suitable relative densities, to avoid the IG prey mortality and increase mortality of mosquito prey.

\section{References}

ADITYA G., BHATTACHARYA S., KUNDU N., SAHA G.K., 2005 Frequency dependent prey selection of predacious water-bugs on Armigeris subalbatus immatures. - J. Vec. Borne. Dis. 42: 9-14.

ADITYA G., BHATTACHARYA S., KUNDU N., SAHA G.K., RAUT S.K., 2004 - Predatory efficiency of the water bug Sphaerodema annulatum on mosquito larvae (Culex quinquefasciatus) and its effect on adult emergence. - Biores. Technol. 95: 169-172.

ARIM M., MARQUET P.A., 2004 - Intraguild predation: A widespread interaction related to species biology. - Ecol. Lett. 7: 557-564.

BALFOUR R.A., BUDDLE C.M., RYPSTRA A.L., WALKER S.E., MARSHALL S.D., 2003 - Ontogenetic shifts in competitive interactions and intraguild predation between two wolf spider species. - Ecol. Entomol. 28: 25-30.

BAMBARADENIYA C.N.B., EDIRISINGHE J.P., SILVA D.N., GUNATILLEKE
C.V.S., RANAWANA K.B., WIJEKOON S., 2004 - Biodiversity associated with rice agro-ecosystem in SriLanka. - Biodivers. Conserv. 13: 1715-1753.

BANERJEE S., ADITYA G., SAHA N., SAHA G.K., 2010 - An assessment of macroinvertebrate assemblages in mosquito larval habitats-space and diversity relationship. - Environ. Monitor. Assess. 168: 597-611.

BENCE J.R., 1988 - Indirect effects and biological control of mosquitoes by mosquitofish. - J. Appl. Ecol. 25: 505-521.

BLAUSTEIN L., 1992 - Larvivorous fishes fail to control mosquitoes in experimental plots. - Hydrobiologia 232: 219-232.

BLAUSTEIN L., KIFLAWI M., EITAM A., MANGEL M., COHEN J.E., 2004 Oviposition habitat selection in response to risk of predation in temporary pools: mode of detection and consistency across experimental venue. - Oecologia. 138: 300-305.

BORER E.T., BRIGGS C.J., MURDOCH W.W., SWARBRICK S.L., 2003 Testing intraguild predation theory in a field system: does numerical dominance shift along a gradient of productivity? - Ecol. Lett. 6 : 929-935

BURLEY L.A., MOYER A.T., PETRANKA J.W., 2006 - Density of an intraguild predator mediates Feeding group size, Intraguild egg predation and intra-and interspecific competition. - Oecologia. 148: 641-649.

CRUMRINE P.W., 2005 - Size structure and substitutability in an odonate intraguild predation system. - Oecologia. 145: 132-139.

CRUMRINE P.W., CROWLEY P.H., 2003 - Partitioning components of risk reduction in a dragonfly-fish intraguild predation system. Ecology. 84: 1588-1597.

DALE P.E.R., KNIGHT J.M., 2008 - Wetlands and mosquitoes: a review. Wet. Ecol. Manage. 16: 255-276.

DAS P.K., SIVAGNANAME N., AMALRAJ D.D., 2006 - Population interactions between Culex vishnui mosquitoes and their natural enemies in Pondicherry, India. - J. Vec. Ecol. 31: 84-88.

DE CLERCQ P., PEETERS I., VERGAUWE G., THAS 0., 2003 - Interaction between Podisus maculiventris and Harmonia axyridis, two predators used in augmentative biological control in greenhouse crops. BioControl 48: 39-55.

DENNO R.F., GRATTON C., PETERSON M.A., LANGELLOTTO G.A., FINKE D.L., HUBERTY A.F., 2002 - Bottom- up forces mediate natural-enemy impact in a phytophagous insect community. - Ecology. 83: 1443-1458.

FLYNN K.E., MOON D.C., 2011 - Effects of habitat complexity, prey type, and abundance on intraguild predation between larval odonates. Hydrobiologia 675: 97-104.

HAMPTON S.E., GILBERT J.J., 2001 - Observations of insect predation on rotifers. - Hydrobiologia 446/447: 437-444.

HOLBROOK C.T., PETRANKA J.W., 2004 - Ecological interactions between Rana sylvatica and Ambystoma maculatum: evidence of interspecific competition and facultative intraguild predation. Copeia 2004: 932-939.

HURLBERT S.H., 1984 - Pseudoreplication and the design of ecological field experiments. - Ecol. Monogr. 54:187-211.

LAWLER S.P., DRITZ D.A., 2005 - Straw and winter flooding benefit mosquitoes and other insects in a rice agroecosystem. - Ecol. Appl. 15: 2052-2059.

LUPI D., ROCCO A., ROSSARO B., 2013 - Benthic macroinvertebrates in Italian rice fields. - J. Limnol. 72: 184-200.

OHBA S., NAKASUJI F., 2007 - Density-mediated indirect effects of a common prey, tadpole on interaction between two predatory bugs: Kirkaldyia deyrolli and Laccotrephes japonensis. - Popul. Ecol. 49: 331-336.

OHBA S., SWART C.C., 2009 - Intraguild predation of water scorpion Laccotrephes japonensis (Nepidae: Heteroptera). - Ecol. Res. 24:1207-1211. 
OKUYAMA T., RUYLE R.L., 2003 - Analysis of adaptive foraging in an intraguild predation system. - Web. Ecol. 4: 1-6.

POLIS G.A., MYERS C.A., HOLT R.D., 1989 - The ecology and evolution of intraguild predation: potential competitors that eat each other. Annu. Rev. Ecol. Syst. - 20: 297-330.

ROSENHEIM J.A., CORBETT A., 2003 - Omnivory and the indeterminacy of predator function: can a knowledge of foraging behaviour help? - Ecology. 84: 2538-2548.

SAHA N., ADITYA G., BAL A., SAHA G.K., 2007a - A comparative study of predation of three aquatic hemipteran bugs on Culex quinquefasciatus larvae. - Limnology. 8: 73-80.

SAHA N., ADITYA G., BAL A., SAHA G.K., 2007b - Comparative study of functional response of common Hemipteran bugs of East Calcutta wetlands, India. - Int. Rev. Hydrobiol. 92: 242-257.

SAHA N., ADITYA G., BAL A., SAHA G.K., 2008 - Light and habitat structure influences predation of Culex quinquefasciatus larvae by the water bugs (Hemiptera: Heteroptera). - Insect. Sci. 15: 461-469.

SAHA N., ADITYA G., SAHA G.K., 2009 - Habitat complexity reduces vulnerability of preys: an experimental analysis using aquatic insect predators and dipteran immatures. - J. Asia. Pacific. Entomol. 12: 233-239.

SAHA N., ADITYA G., SAHA G.K., HAMPTON S.E., 2010 - Opportunistic foraging by heteropteran mosquito predators. - Aquat. Ecol. 44: 167-176.

SIH A., ENGLUND G., WOOSTER D., 1998 - Emergent impacts of multiple predators on prey. - Trends. Ecol. Evol. 13: 350-355.

SOLUK D.A., 1993 - Multiple predator effects: predicting combined functional response of stream fish and invertebrate predators. Ecology. 74: 219-225.
SOLUK D.A., COLLINS N.C., 1988 - Synergistic interactions between fish and stoneflies-facilitation and interference among stream predators. - Oikos. 52: 94-100.

SUNISH I.P., REUBEN R., 2002 - Factors influencing the abundance of Japanese encephalitis vectors in rice fields in India-II. Biotic. Med. Vet. Entomol. 16: 1-9.

WALLS S.C., WILLIAMS M.G., 2001- The effect of community composition on persistence of prey with their predators in an assemblage of pond-breeding amphibians. - Oecologia. 128: 134-141.

WALZER A., PAULUS H.F., SCHAUSBERGER P., 2004 - Ontogenetic shifts in intraguild predation on thrips by phytoseiid mites: the relevance of body size and diet specialization. - Bull. Entomol. Res. 94: 577-584.

WISSINGER S., MCGRADY J., 1993 - Intraguild predation and competition between larval dragonflies: direct and indirect effects on shared prey. - Ecology. 74: 207-218.

WISSINGER S.A., 1992 - Niche overlap and the potential for competition and intraguild predation between size-structured populations. Ecology. 73: 1431-1444.

YEE D.A., 2010 - Behavior and aquatic plants as factors affecting predation in three species of larval predaceous diving beetles (Coleoptera: Dytiscidae). - Hydrobiologia. 637: 33-43.

YEE D.A., TAYLOR S., VAMOSI S.M., 2009 - Beetle and plant density as cues initiating dispersal in two species of adult predaceous diving beetles. - Oecologia. 160: 25-36.

ZAR J.H., 1999 - Biostatistical analysis. IV ed. - Pearson Education (Singapore) Pte. Ltd., (Indian Branch), New Delhi: 663. 